\title{
The Effects of Spatial Legacies following Shifting Management Practices and Fire on Boreal Forest Age Structure
}

\author{
Patrick M. A. James,${ }^{1, *}$ Marie-Josée Fortin, ${ }^{2}$ Andrew Fall, ${ }^{3}$ Dan Kneeshaw, ${ }^{4}$ \\ and Christian Messier ${ }^{4}$
}

\begin{abstract}
${ }^{1}$ Faculty of Forestry, University of Toronto, 33 Willcocks St., Toronto, Ontario M5S 3B3, Canada; ${ }^{2}$ Department of Ecology and Evolutionary Biology, University of Toronto, 25 Harbord St., Toronto, Ontario M5S 3G5, Canada; ${ }^{3}$ Gowlland Technologies Ltd, 220 Old Mossy Road, Victoria, British Columbia V9E 2A3, Canada; ${ }^{4}$ Centre d'étude de la forêt (CEF), Université du Québec à Montréal, Case postale 8888, Succursale Centre-ville, Montreal, Quebec H3C 3P8, Canada
\end{abstract}

\begin{abstract}
Forest age structure and its spatial arrangement are important elements of sustainable forestry because of their effects on biodiversity and timber availability. Forest management objectives that include specific forest age structure may not be easily attained due to constraints imposed by the legacies of historical management and natural disturbance. We used a spatially explicit stochastic model to explore the synergetic effects of forest management and fire on boreal forest age structure. Specifically, we examined (1) the duration of spatial legacies of different management practices in the boreal forest, (2) how multiple shifts in management practices affect legacy duration and the spatial trajectories of forest age structure, and (3) how fire influences legacy duration and pattern development in combination with harvesting. Results based on 30 replicates of 500 years for each scenario indicate that (1) spatial legacies persist over 200 years and the rate at which legacies are overcome depends on
\end{abstract}

whether new management targets are in synchrony with existing spatial pattern; (2) age specific goals were met faster after multiple management shifts due to the similar spatial scale of the preceding management types; (3) because large fires can erase the spatial pattern created by smaller disturbances, scenarios with fire had shorter lags than scenarios without fire. These results suggest that forest management goals can be accelerated by applying management at a similar spatial scale as existing spatial patterns. Also, management planning should include careful consideration of historical management as well as current and likely future disturbances.

Key words: stochastic spatially explicit model; landscape pattern metrics; ordination; simulation modeling; landscape legacies; forest disturbance; forest management; forest age structure.
Received 23 October 2006; accepted 12 September 2007; published online 9 October 2007.

*Corresponding author; e-mail: Patrick.james@utoronto.ca; Patrick.ma. james@gmail.com

\section{INTRODUCTION}

Forest management in Canada is currently embracing an ecological perspective wherein values such as the maintenance of wildlife and biodiversity are included in management planning in 
addition to timber production (Galindo-Leal and Bunnell 1995; Bergeron and others 1999, 2002; Kneeshaw and others 2000). To operationally meet these goals in the boreal forest it has been proposed that forest management should create openings with sizes and frequency similar to those created by natural disturbances such as fire. It is assumed that the maintenance of a historical distribution of forest ages and patch sizes at the landscape scale will act as a coarse scale filter to maintain biodiversity (Hunter 1993; Burton and others 1999; Messier and Kneeshaw 1999). Although these changes are heralded as an important paradigm shift in managing natural systems, ecosystem management goals may never be achieved because spatial structure created by historical management and disturbances influence the rate at which new management goals become reality ( $\mathrm{Li}$ and others 1993). Increasingly rapid changes in methods of forest management necessitate an increased understanding of how historical legacies influence new management practices and how multiple shifts in management strategies cumulatively affect longterm spatial forest dynamics.

The spatial legacies of interactions between management and natural disturbance can constrain management options because they temporarily limit the availability of parts of the landscape for management in terms of accessibility, composition (for example, age and species), and spatial configuration. Alteration of these attributes due to repeated changes in management can have a long lasting influence on natural ecosystem processes. Whether these influences are positive or negative will depend on the specific changes made.

Repeated changes in management can create complex spatial legacies that may make it difficult to achieve new management goals (Wallin and others 1994). Such constraints may not be evident during planning if aspatial models (that is, models based on yield only and not spatial contiguity) are used for planning support. Difficulties in achieving new management goals arise when they are not in synchrony with existing patterns and are exacerbated by on-going dynamic interactions among human and natural disturbances. The period of transition between initial and target conditions represents the legacy of historical conditions, the duration of which is a function of forest type, past management and disturbance effects, and current management.

Anticipating the effects of spatial legacies on management goals and long-term forest dynamics can be difficult because the relationship between disturbances and spatial pattern can be additive, multiplicative, or non-linear (Fortin and Dale 2005; Didion and others 2007). Several studies have shown that legacies in forest structure and composition persist after the rules governing forest management (for example, legislation) have changed and that these legacies interact with future management activities and disturbances (for example, Li and others 1993; Wallin and others 1994; Gustafson and others 2004). Significant ecological and economic consequences can be expected with such changes (Gustafson 1998; Friedman and Reich 2005). However, there has been little research into how multiple changes in management can cumulatively affect forest age structure in a boreal mixed-wood forest and the implications of such effects for long-term sustainability. For new management practices to be useful for sustainable forest management, interactions among multiple policies and natural processes over long-time horizons need to be examined.

We investigated how multiple shifts in landscape scale forest management practices affect the duration and impact of spatial legacies using a simulation model of a boreal mixed-wood forest in Québec as a case study. Specifically, we addressed the following three research questions: (1) How long do spatial legacies of a management strategy persist after a switch to a new management strategy? (2) How might multiple shifts in management cumulatively affect legacy duration and potential forest development trajectories? And (3), how does fire affect legacy duration and the cumulative effects of shifting management?

Forest age structure is frequently used as a coarse scale indicator of biodiversity due to its implicit reflection of site history, strong correlation with other indicators of biodiversity, effects on forest resilience and disturbance dynamics, and obvious sensitivity to management activities (Franklin and Forman 1987; Fall and others 2004). Because of this, simulation results from our scenarios were compared using a set of landscape pattern metrics (McGarigal and Marks 1995) that tracked changes in spatial forest age structure through time in response to different management practices.

\section{METHODS}

\section{Study Area}

We investigate the spatial dynamics of the Vermillion region, a boreal mixed-wood forest region in south central Québec (Figure 1) that covers approximately $430,000,392,000$ ha of which is forested. The study area contains two distinct forest 


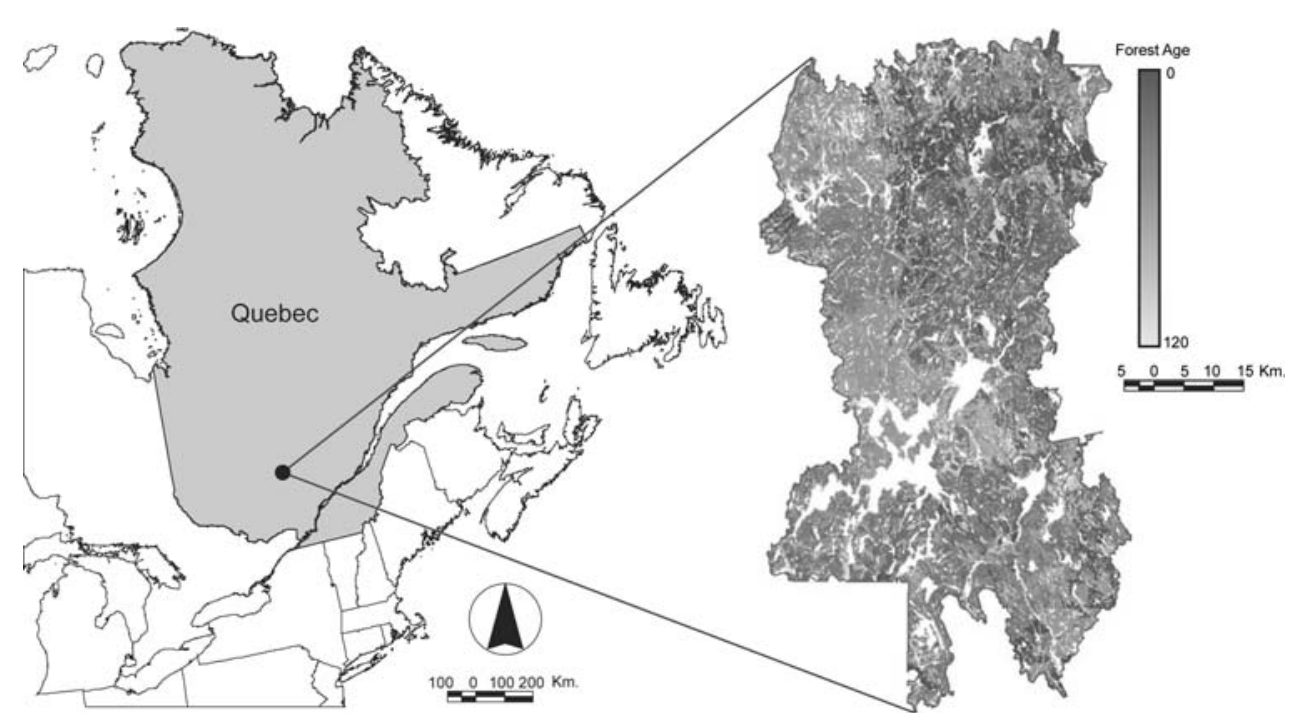

Figure 1. Vermillion landscape study region in Québec, Canada showing variability in forest age. Lighter shades of grey represent older patches of forest. Study area is approximately 430,000 ha. Each pixel is $50 \mathrm{~m} \times 50 \mathrm{~m}$.

types. The northern portion consists of 180,000 forested ha within the "Missinabi-Cabonga" region (Rowe 1972), characterized by coniferous boreal forest with interspersed species found in the Great Lakes-St. Lawrence Forest to the south. Dominant species include black spruce [Picea mariana (Mill.) B.S.P.)], balsam fir [Abies balsamea (L.) Mill.], jack pine (Pinus banksiana Lamb.) and white birch (Betula papyrifera Marsh.). The southern portion is classified as "Laurentian" forest and consists of approximately 210,000 forested ha. The southern region is described as a transition zone between the boreal and temperate forest regions (Rowe 1972). Characteristic species of this region include, balsam fir, white spruce (Picea glauca (Moench) Voss), and yellow birch (Betula alleghaniensis Britt.). The region has moderately rugged topography as well as a high density of lakes and wetlands (approximately 10\% in total).

The historically dominant agents of disturbance in this region are stand replacing fire (Bergeron and others 2001), intermediate scale disturbances such as wind-throw, and episodic outbreaks of diseases and forest insects such as spruce budworm (Gray and others 2000; Bouchard and others 2007). Presently, logging also contributes as an agent of forest change. Current tree age and species composition and configuration in the Vermillion region reflect a relatively long history of forest management and its complex interactions with succession and natural disturbance.

Data for the initial conditions used in all modeling scenarios were derived from the third decadal forest inventory (1990s) carried out by SIFORT (Système d'Information FORestière par Tesselle) in collaboration with the Québec Ministry of Natural Resources and Abitibi-Consolidated. Spatial data were derived from supervised classification of aerial photography and are represented in digital raster format at a resolution of $50 \mathrm{~m} \times 50 \mathrm{~m}$.

\section{Vermillion Landscape Model}

The Vermillion Landscape Model (VLM) is a spatially explicit stochastic model that uses historical succession, growth, yield, and fire information to simulate landscape scale forest dynamics. The VLM is comparable to the LANDIS simulation model (He and Mladenoff 1999) in that multiple processes are iteratively simulated using a fixed timestep in a spatial, raster context. The VLM departs from LANDIS in that it does not explicitly include seed dispersal and colonization to determine forest succession but instead uses empirically derived transition probabilities to drive a semi-Markov chain succession module (described below).

The VLM was implemented using the SELES modeling platform (Fall and Fall 2001) and has been previously used to investigate interactions between forest management and fire (Fall and others 2004; Didion and others 2007). Here, the VLM was used to examine the effects of changing management practices on the development of spatial structure in forest age. Sub-models for fire, forest growth, and succession are included to explore the spatial interactions among natural processes and three different types of forest management. To examine how the spatial patterns created by each management type change over time in the presence and absence of fire, 30 replicates for each of 11 scenarios were simulated for 500 years using a 5-year timestep. This number of replicates was chosen based on pilot studies in which it was noted that no further stochastic var- 
iation was captured in the fire submodel with further replicates.

\section{Sub-Model Descriptions}

Fire. Stochastic fires are a key agent of change in the boreal forest (Johnson 1992). We used a topdown statistical fire model (Li and others 1997) to simulate stand replacing fires based on mean fire size and fire return interval parameters (Van Wagner 1978; Fall and others 2004). Here, the mean annual number of fires was defined as: landscape size/(fire return interval $\times$ mean fire size). Our goal was to simulate the spatial effects of stand-replacing crown fires at the landscape scale based on historical information for the study area. In this model, fires burn independent of terrain, weather, and site conditions, including forest age.

Fires that burn independent of forest age is a common simplifying assumption in studies of the boreal forest (Van Wagner 1978; Boychuk and others 1997) because boreal forest age structure is often exponentially distributed (Van Wagner 1978; Bergeron and others 2004a). If the long-term average forest age structure can be characterized as an exponentially distributed variable, several known statistical properties of this distribution require independence among fire events (Johnson and Van Wagner 1985; Boychuk and others 1997). By controlling the distribution of fire sizes and return intervals we implicitly simulate the effects of forest fuels and weather on the fire regime given that our parameter estimates come from regional historical data (Lefort and others 2003).

The assumption of age-independence is also related to the behavior of large, stand-replacing crown fires. Stand-replacing fires in boreal forests are strongly linked to extreme weather events during which fires burn young and old stands alike (Johnson and others 2001; Lefort and others 2003). Such fires account for more than $97 \%$ of the area burned although they account for less than $5 \%$ of the total number of fires (Stocks and others 2002).

Variability in the fire regime was included by stochastically selecting the number of fires per year and fire size from negative exponential distributions parameterized for the study region. Mean fire size was set at 1,500 ha (Fall and others 2004). Fires ignite randomly on the landscape and spread to adjacent cells until the total area burned reaches the pre-selected size. Fires cannot spread over water or cells that burned during the current timestep (that is, within the previous 5 years). The fire return interval was set at 250 years (Bergeron and others 2001) to reflect recent modifications in cli- mate. We also simulated a historical fire return interval of 150 years (Bergeron and others 2001) to test model sensitivity and to compare the forest age class distribution created by historical fire conditions without management to that created by the estimated current fire return interval.

From a modelling perspective, an age-independent statistical fire model was desirable to reduce model complexity so that the effects of different management practices were not confounded by uncertain variability in the fire regime. In this model variability in fire size and frequency are not emergent properties, but are instead input as control parameters. Although fine-scale variability in forest fuels and weather can influence fire dynamics, we do not have the information to accurately simulate such processes at the scale of our study area and simulation duration. If we were to include such details we would be more precise, but not necessarily more accurate because of uncertain fire-fuel-weather interactions that are beyond the scope of this paper.

Forest Growth and Succession. Successional pathways were defined as a function of site-specific soil and drainage conditions and previous vegetation based on long-term plot level transition data and forest inventory in the Vermillion region. Succession was modeled as a semi-Markov process that replaces stands killed by logging or fire. The succession model also tracks stand age and volume accumulation. Volume of growing stock in each cell is based on input yield curves, soil and drainage conditions, and stand age. Following a stand replacing disturbance, cell age and volume are set to zero, and a new successional trajectory that contains up to a maximum of six species transitions is assigned. A cell does not deviate from this successional trajectory until another disturbance resets stand age. In the absence of disturbance, cells continue to age to a maximum of 300 years and site-specific maximum volume. Because this study focuses on spatial patterns in forest age, further details on the dynamics of species succession are not directly relevant here. Although micro-site and stand level disturbance processes such as gap dynamics, insects, and disease play an important role in forest dynamics, they are not included in our simulation model; we focus on comparing the effects of landscape scale processes (that is, logging and fire) on forest age structure.

Harvest. Operating areas were used to simulate active harvesting zones and operational constraints (for example, machinery location, fuel) to prevent overly dispersed logging patterns. An operating area is represented as a circle on the landscape with an area of 25,000 ha that is active for 20 years, 
Table 1. List of Simulation Scenarios Analyzed

\begin{tabular}{lllll}
\hline Scenario \# & Management type & Fire & Fire return interval $^{\mathbf{1}}$ & Scenario code \\
\hline 1 & Block cut & Yes & 250 & BC-Fire \\
2 & Block cut & No & - & BC-noFire \\
3 & Strip cut & Yes & 250 & SC-Fire \\
4 & Strip cut & No & - & SC-noFire \\
5 & Age targeted & Yes & 250 & AT-Fire \\
6 & Age targeted & No & - & AT-noFire \\
7 & Protected area-no harvest & Yes & 150 & PA-FireHist \\
8 & Protected area-no harvest & Yes & 250 & PA-Fire \\
9 & Protected area-no harvest & No & - & PA-noFire \\
10 & Shifting management & Yes & 250 & Shift-Fire \\
11 & Shifting management & No & - & Shift-noFire
\end{tabular}

The shifting management scenarios included 50 years of block cut management (BC), 30 years as strip cut management (SC), followed by age class targeted management for the duration of simulation.

${ }^{1}$ Fire return interval refers to parameterization of the fire sub-model and represents the expected length of time to burn an area equal in size to the study area. PA-FireHist refers to the historical fire return interval. See text for further details.

after which it is deactivated and new operating areas are reassigned. Up to five operating areas are active at any given time during simulation. By preferentially harvesting within an operating area, harvest blocks that are close in time will also tend to be close in space.

In addition to operating areas, timber harvest in the VLM is constrained by an area-based annual allowable cut (AAC), a site specific minimum harvest age at which a cell reaches merchantable volume, and road accessibility constraints. AAC is interpreted in this study as a percentage of the total productive forest area to be harvested each year and was set at $1 \%(\sim 3,900 \mathrm{ha})$. We used an area-based AAC instead of a volume based AAC for two reasons: (1) to keep the target spatial extent of logging constant and (2) so that we could examine how different management types affect forest age structure without the potentially confounding effects of variation in area accessed. Harvest blocks are built up from individual cells. Blocks are placed preferentially around cells that have high wood volume, are within $2 \mathrm{~km}$ of an existing road, and are within an active operating area. Although block locations are constrained by road access, simple road construction can make initially inaccessible regions accessible over time. Cells with the same "preference" value have equal probability of block initiation. Once initiated, blocks are "grown" using neighboring cells until they reach their pre-selected size chosen from a uniform distribution between 5 and 60 ha.

\section{Scenarios}

We investigated eleven scenarios using the VLM composed of five management types each simu- lated with and without fire as well as a historical fire scenario. These 11 scenarios are summarized in Table 1. The five management types are: (1) block cuts (BC), (2) strip cuts (SC), (3) age-class targeted cuts (AT), (4) no management, or "protected area" (PA), and (5) a combination of the following three management types through time; 50 years of $\mathrm{BC}$ followed by 30 years of SC followed by AT, hereafter referred to as "shifting management." These practices were selected to reflect current and recent management practices in Québec.

Block cut (BC) management targets a regulated, even-aged forest with a mean age equal to the rotation length (that is, 100 years). BC management harvests a constant percentage of forest (AAC) each year in large blocks and is constrained by minimum harvest ages and road access. Strip cutting (SC) is similar to BC with regard to AAC and minimum harvest age but harvests in linear, $50 \mathrm{~m}$ (that is, one cell) wide strips within the harvest block and leaves areas between strips of the same width. After a specified minimum re-entry interval (25 years) harvesting of the leave areas may occur. For simplicity, strips are all harvested in a north-south direction. Age-class targeted management (AT) behaves like $\mathrm{BC}$, but prioritizes the maintenance of an exponential distribution of cell ages at the landscape scale similar to that expected under the natural fire regime (Bergeron and others 1999; Burton and others 1999). No other novel spatial constraints (for example, adjacency of different age components, block shape constraints) are included in AT management. Figure 2 contrasts the age class structure targets of (a) BC and SC management, and (b) AT. Within each timestep, the harvest model determines which age classes are 

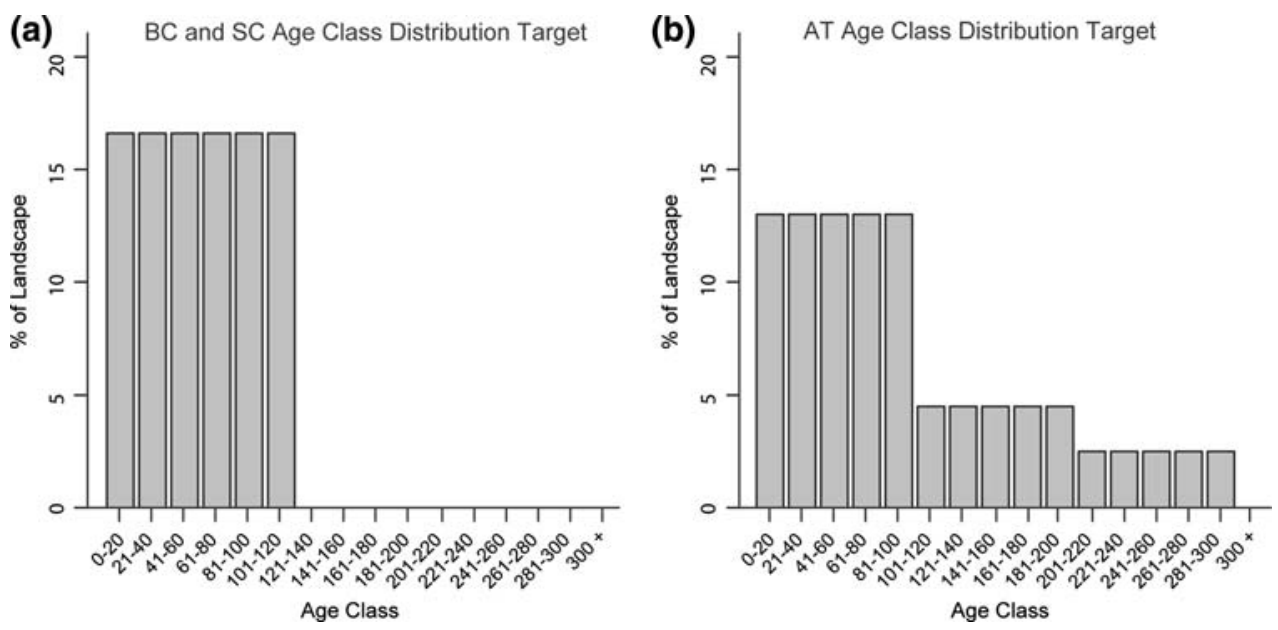

Figure 2. Target age class distributions of a block cut (BC) and strip cut (SC) management and $\mathbf{b}$ age class targeted (AT) management (from Bergeron and others 1999). in deficit given the age class target of the management type being implemented and preferentially logs sites that will help achieve that target. Figure 3 shows several examples of simulated forest landscapes under different management using the VLM.

\section{Initial Conditions}

All scenarios started with the same initial conditions. Initial forest age class structure is relatively even-aged, likely as a result of historical management in the area directed towards a regulated forest to ensure a steady flow of timber. Most of the forest is less than 100 years old $($ mean $=53$, std. dev. $=$ 29). The small amount of forest greater than 100 years old ( 13,700 ha) that is present is highly fragmented. Initial conditions are represented in all panels in Figure 4 as "Year 0."

\section{Analysis}

Six landscape pattern metrics were used to characterize and compare changes in forest age structure over time in response to different management-fire combinations (McGarigal and Marks 1995). These metrics were selected based on their ability to capture three biologically relevant components of spatial pattern in age $\left(\mathrm{O}^{\prime} \mathrm{Neil}\right.$ and others 1988; D'Eon and Glenn 2005; Nonaka and Spies 2005): (1) amount, (2) edge, and (3) connectivity of patches (Fahrig 2003). Table 2 summarizes the categories of spatial pattern and describes the corresponding metrics. The six metrics were: (1) percent of landscape, (2) total patch core area, (3) number of patches, (4) edge density, (5) mean core area per patch, and (6) area weighted minimum planar graph. The area weighted minimum planar graph (AWMPG) is a graph theoretic measure of landscape connectivity based on the sum of the lengths of the set of non-crossing links that connect all patches and minimizes total link length, weighted by the summed area of connected patches (James and others 2005; O’Brien and others 2006). A non-crossing link is a link between two patches in a network that does not intersect any other links. AWMPG has a high value when small patches are separated by large distances and a low value when large patches are close together. Together, these metrics represent a simple set of interpretable spatial response variables given the high correlation typically found among indices of landscape pattern (Remmel and Csillag 2003).

These metrics were calculated for maps produced at 50-year intervals (10 intervals per simulation) within each replicate (30 replicates) of each scenario (11 scenarios) for a total of 3,300 maps. Within each map forest age was classified into three categories (Bergeron and others 1999): "Young" (1-100 years), "Intermediate" (101-200 years), and "Old" (301+ years).

Two aspatial harvest metrics, \% TARGET MET and MEAN HARVEST AGE, were calculated and output in 5-year intervals for each replicate to assess the influence of the different management types on timber supply. Changes in \% TARGET MET reflects how landscape constraints can limit the implementation of management strategies. MEAN HARVEST AGE was tracked to investigate whether changes in different management practices affect the age at which trees are cut and reflects potential changes in timber quality (for example, tree and piece sizes).

\section{Ordination-Principal Components Analysis (PCA)}

The mean value of each landscape metric over all replicates for each age category was summarized relative to the different management types at 50- 

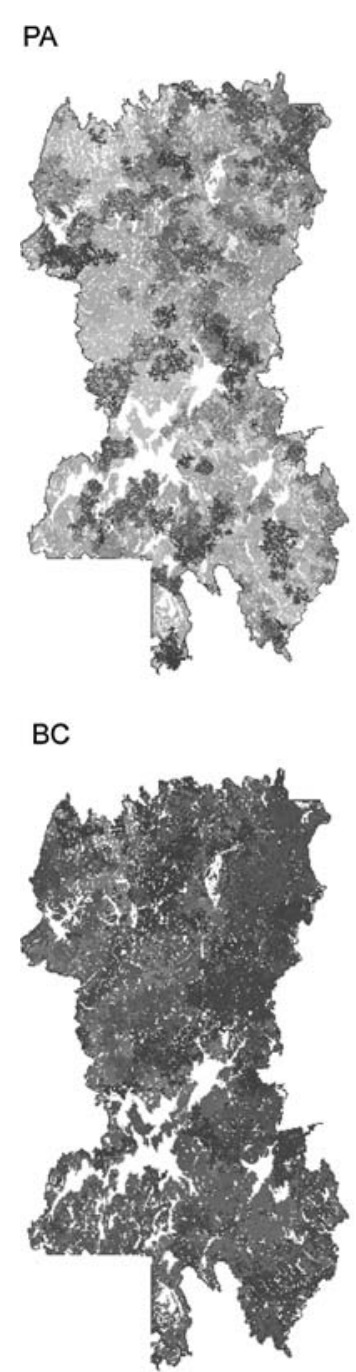

AT

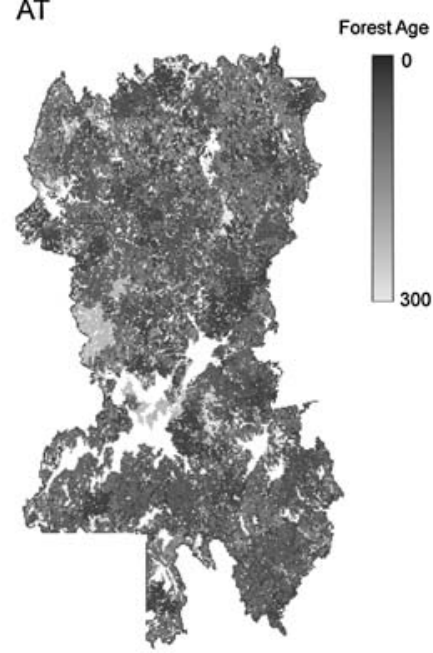

SC

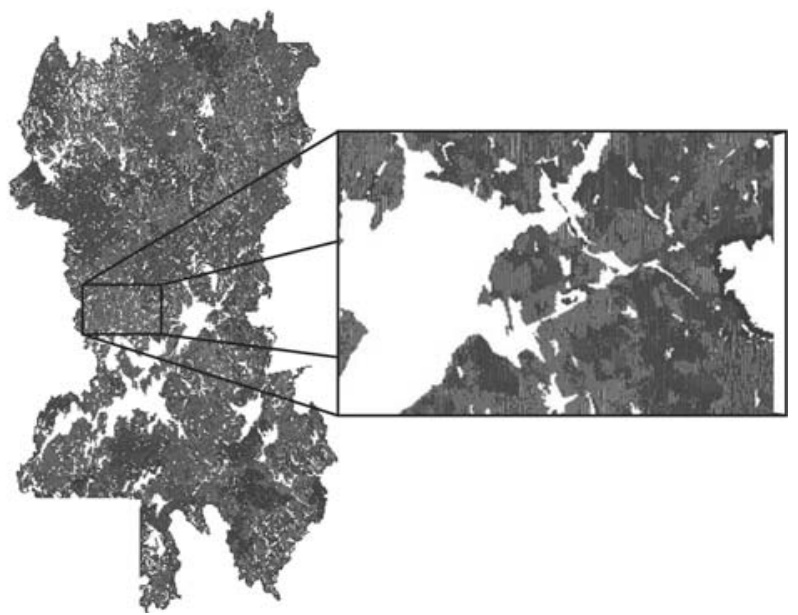

Figure 3. Series of example maps showing different spatial outputs of forest age in response to the different types of forest management. Lighter shades of grey represent older patches of forest. All maps show output at simulated year 100 from a single stochastic realization of the model. The map labelled PA displays protected area management, that is, no harvest; $B C$ block cut management, $S C$ strip cut management, $A T$ age class targeted management. Inset to the bottom right shows the fine scale heterogeneity in northsouth strips left behind by SC management. year intervals using PCA. These ordinations summarize the temporal development of spatial pattern in our management scenarios, hereafter referred to as a spatial trajectory to distinguish it from a successional trajectory used in the succession model. PCA has been used in several other studies to summarize landscape pattern metrics (D`Eon and Glenn 2005; Nonaka and Spies 2005). Ordination using PCA reduces the dimensionality of complex data, exposes intrinsic gradients, and allows such data to be interpreted diagrammatically (Pielou 1984). Points in our PCA diagrams summarize the spatial trajectories of the different treatments through time and ordination space. PCA was selected over detrended correspondence analysis (DCA) because initial exploration revealed short gradients (Jongman and others 1987). Ordination analysis was performed using the "princomp" function of the package "stats" for R (R-Foundation 2005).

The broken stick criterion was used to assess significance of ordination axes and significance of loadings within each significant axis to facilitate meaningful interpretation of the principal components (Jackson 1993; Peres-Neto and others 2003). The broken stick criterion for axis and loading significance is based on comparison of observed values with eigenvalues from random data.

\section{RESUlts}

Fire

Two different baseline fire simulations were run to examine the effects of fire frequency on landscape pattern without logging. Figure $4 a$, b contrast the development of age class structure using a historical fire return interval (150 years) and the estimated current fire return interval (250 years) (Bergeron and others 2001). At year 300 the current fire return interval results in more old forest (that is, forest that has escaped fire) than the historical fire regime. Mean forest age of the landscape 
(a) $P A$ with Fire $(F R I=150)$

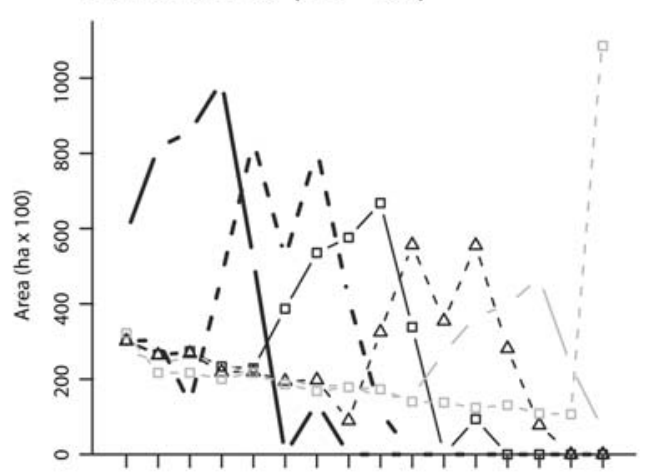

(c) BC with Fire
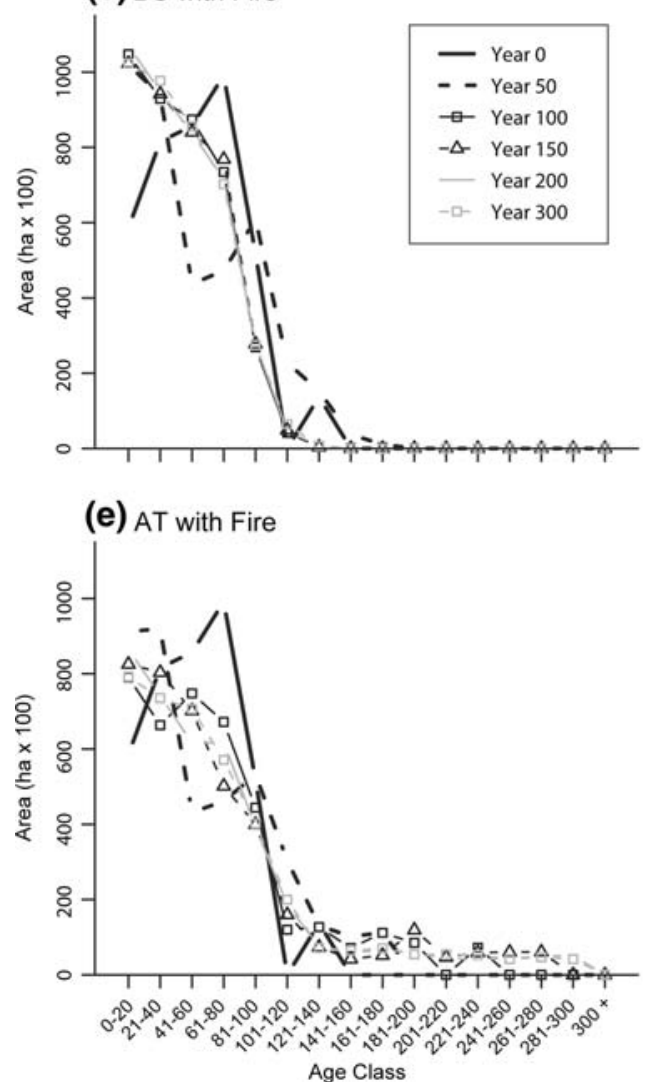

(b) PA with Fire (FRI = 250)

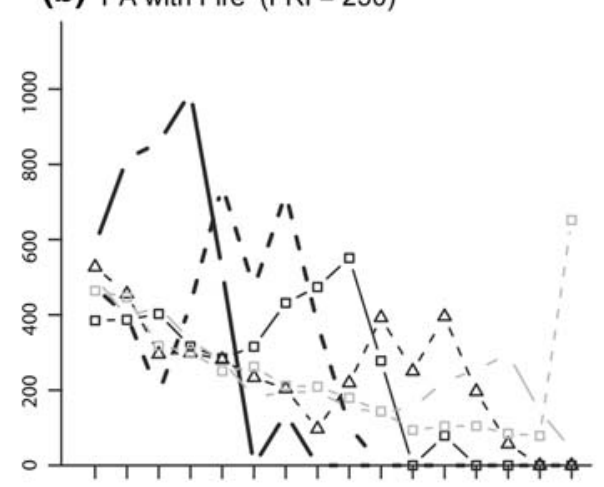

(d) SC with Fire

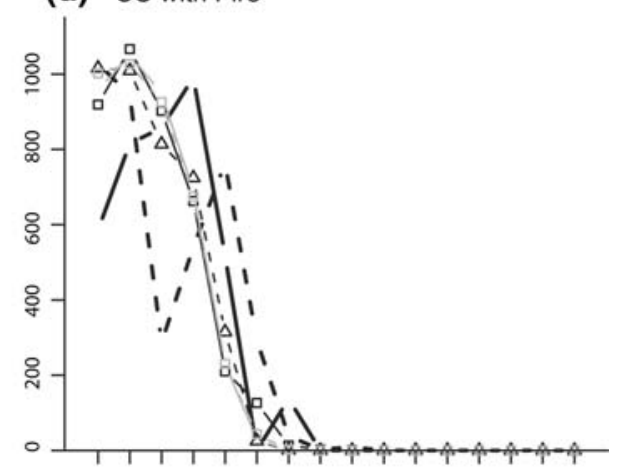

(f) Shifting Management with Fire

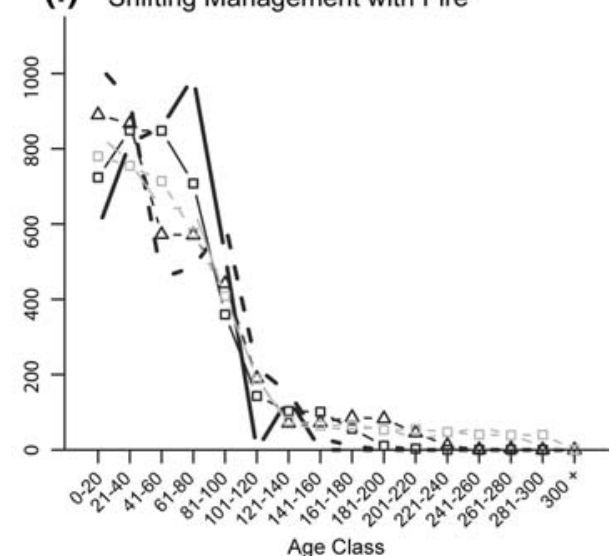

Figure 4. Mean area of forest in 20-year age classes over 30 replicates of management with fire and fire only simulations (that is, no harvest-PA). a, b Show age class distribution development with fire using (a) a current fire return interval (FRI) of 150 years, and $\mathbf{b}$, a historical FRI of 250 years. Management strategies shown are: $B C$ block cuts, $S C$ strip cuts, $A T$ age class targeted harvest, and shifting management (see text). Series shown represent the forest age-class distribution at initial conditions and following 50, 100, 150, 200, 250, and 300 years of simulation. subject to the current fire regime at year 300 was 130 years $($ std. dev. $=97.87$ ) compared to a mean age of 111.5 years (std. dev. $=93.62$ ) in the historical simulation. Although these values are not dramatically different, a key difference is shown in Figure $4 \mathrm{~b}$ where the age distribution has a much larger tail in the oldest age class because we did not track age beyond 300 years.

\section{Forest Age Class Structure}

The age class targets of each management type (BC, SC, AT) were met by year 300, but reached at dif- ferent rates (Figure 4c, d, e). With respect to global age structure, BC and SC management produced nearly identical results and reached their target distribution in fewer than 100 years (Figure 4c, d). $\mathrm{AT}$ and the shifting management scenarios took the longest to reach their target distribution and developed similarly, reaching their goals only after 300 years (Figure 4e, f). Age class targets were only met following enough time for the forest to age sufficiently. Scenarios with fire were generally slower to attain their target age structure than those without (not shown). In the fire only scenarios (PA-Fire and PA-FireHist), old forest accrues 
Table 2. List of Landscape Metrics Calculated and Used in PCA Ordination Analysis

\begin{tabular}{|c|c|c|c|}
\hline Category & Pattern metric & Acronym & Description \\
\hline Amount of forest & Percent of landscape & PCTLAND & $\begin{array}{l}\text { Percentage of total area of landscape occupied } \\
\text { by a single patch type }\end{array}$ \\
\hline Amount of forest & Total core area & TCA & Summed amount of patch core over landscape \\
\hline Patch abundance & Patch density & PD & Number of patches per 100 ha \\
\hline $\begin{array}{l}\text { Patch shape and } \\
\text { edge }\end{array}$ & Edge density & ED & Edge length of patches per ha (m/ha) \\
\hline $\begin{array}{l}\text { Patch shape and } \\
\text { edge }\end{array}$ & Mean core area per patch & MCA & $\begin{array}{l}\text { Mean amount of core area among all } \\
\text { patches of a given type }\end{array}$ \\
\hline Connectivity & $\begin{array}{l}\text { Area weighted minimum } \\
\text { planar graph }\end{array}$ & AWMPG & $\begin{array}{l}\text { Area weighted sum of all links in the minimum } \\
\text { planar graph (MPG) among all patches of a } \\
\text { given type (see text) }\end{array}$ \\
\hline
\end{tabular}

as the forest ages and no forest was in the oldest category until over 200 years had passed in the simulation (Figure 4a, c). Without fire or harvesting, all forests ended up at the oldest age category of " $300+$ " after 300 years of simulation (Figure $4 \mathrm{c})$. Because meeting the age-class target is a priority before meeting the AAC target, AT management consistently meets its age-class objectives at an occasional expense of timber as measured by area accessed (see below)

\section{Landscape Metrics}

The six landscape metrics showed distinct changes through time in response to different combinations of management type and fire. Due to the large number of data series generated for the six landscape metrics over the three age categories and in response to four types of forest management, with and without fire, we present the change in only one metric, edge density, over time for each age category as an example (Figure 5). Changes in the other metrics through time were summarized using ordination (PCA). Because BC and SC management typically do not allow forest stands to age beyond 120 years, metric values are approximately zero in the older age categories for those practices (Figure 5e, f). Similarly low values for edge density were found in the scenario without harvesting or fire (PA-noFire; Figure 5b, d). Although similar values are indicated, the metrics actually reflect opposite situations. In the PA scenarios, very low patch density for old forest is observed because most of the forest becomes old and aggregated into a single patch. Conversely, in scenarios with BC or SC management a low ED for older forest age categories reflects the fact that there was virtually no forest of that age. This demonstrates the importance of evaluating multiple landscape metrics to make meaningful assessments of spatial pattern (O`Neil and others 1988; D`Eon and Glenn 2005; Nonaka and Spies 2005) and further exemplifies the utility of an ordination approach.

The AT scenarios allowed more old forest to persist and had higher edge densities for the older age classes than the no management (PA) scenarios. The dearth of older forest in these scenarios was also demonstrated by very high values for AWMPG (data not shown). AT and PA management resulted in lower AWMPG values for older forest categories than $\mathrm{BC}$ or $\mathrm{SC}$, indicating larger patches connected at shorter distances.

\section{PCA}

Changes in landscape pattern metrics in response to different management practices were summarized through time using the first two principal components of the PCA. Figure 6 displays the first two principal components of the scenarios with fire (Figure 6a) and without fire (Figure 6b). The first four axes were found to be significant using the broken stick criterion for both fire and no-fire scenario sets indicating that these axes should be used for interpretation. In scenarios with fire, the first and second principal component axes captured 47.8 and $20.7 \%$ of the variation, respectively. When fire was not included, the first two axes captured 33.5 and $27.3 \%$ of the variation, respectively. Application of the broken stick criterion to assess significance of the individual factor loadings within each significant axis revealed similar gradients for both fire and no-fire simulation sets. Table 3 summarizes the eigenvalues and factor loadings for the four significant axes of the two ordinations. Table entries in bold indicate landscape metrics that contributed significantly to the variance captured by the significant axes and were 

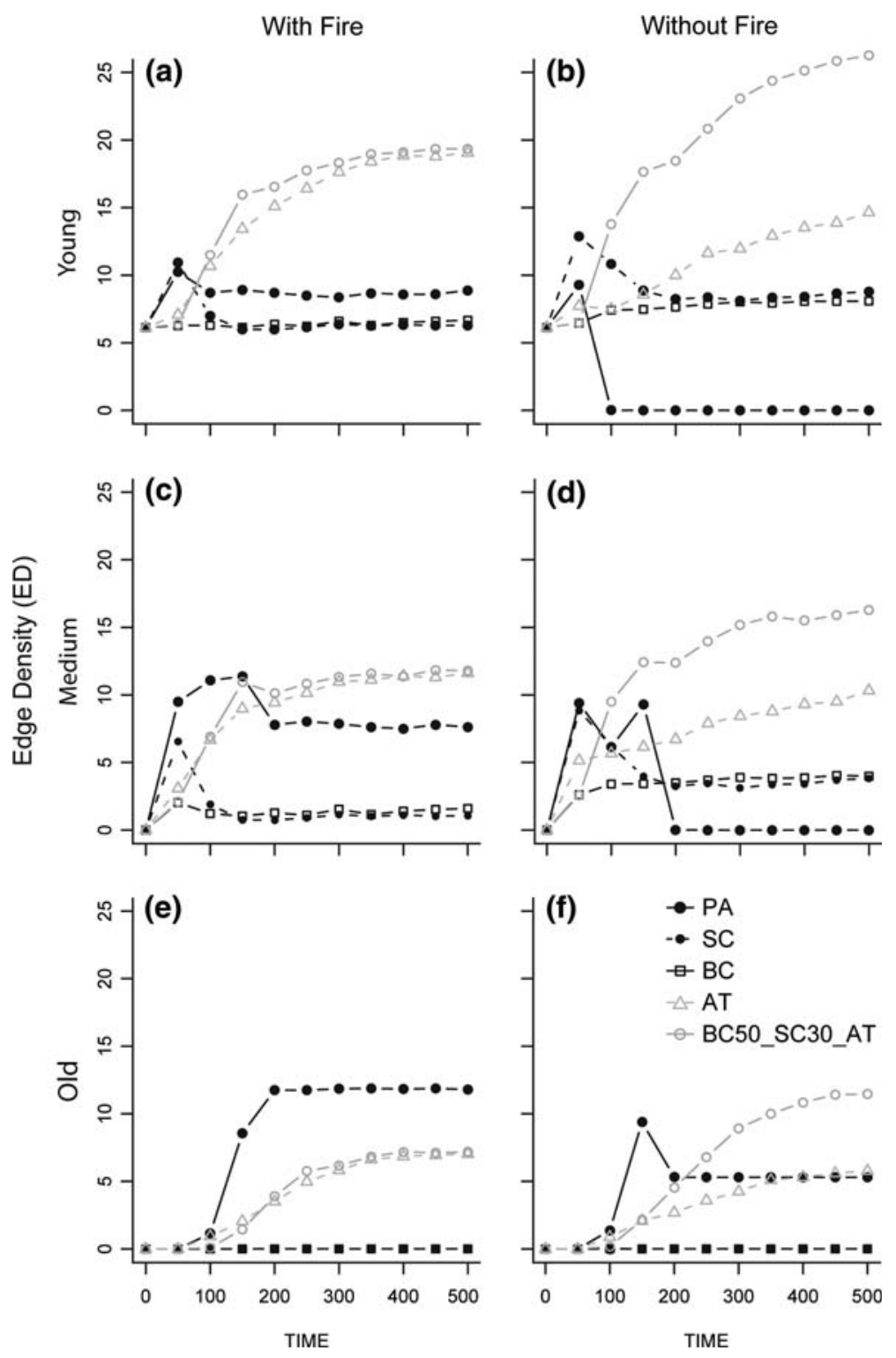

Figure 5. Development of spatial landscape metric Edge Density $(E D)$, over time for three age categories in response to different management practices with fire. "Young" refers to forest 0-100 years old,

"Intermediate" refers to forest between 101 and 200 years old, and "Old" refers to forest greater than 300 years old. Different series in each panel represent different management types: $B C$ block cuts, $S C$ strip-cuts, $A T$ agetargeted management, and $P A$ protected areas, or no harvesting. These data in addition to those for each of the five other landscape metrics were integrated and summarized using principal components analysis (Figure 6). used to interpret the two principal components displayed.

In scenarios with fire, the first principal components axis (PCA axis 1) represents a gradient in forest age, from young forest on the right, to older forest represented by the factor PCT.2 on the left. Intermediate between these two factors is PD.1, which indicates an increased fragmentation of young forest as a result of an increase in older age classes. PCA axis 2 mainly represents a fragmentation gradient with continuous forest located in the upper two quadrants, and patchy forest in the lower two. In scenarios without fire, PCA identified the same gradients (that is, forest age and fragmentation) but associated them with opposite axes. Without fire, PCA axis 1 represents the fragmentation gradient and PCA axis 2 represents the forest age gradient. The separation between composition and fragmentation is more evident without fire.

In both ordination diagrams, all development trajectories originate from initial conditions represented by a star. Each management type separates itself through time into one of three clusters along a specific spatial trajectory that corresponds to its particular spatial attributes. The clusters correspond to (1) SC and BC management, (2) AT management, and (3) no harvesting (PA scenarios). In Figure 6a, b, SC and BC scenarios cluster out near initial conditions relatively quickly and indicate similarity between our harvest model and historical management practices in the region. The spatial trajectory for the AT-Fire scenario moves downward through ordination space far from initial conditions and becomes associated with a highly 


\section{(a) With Fire}

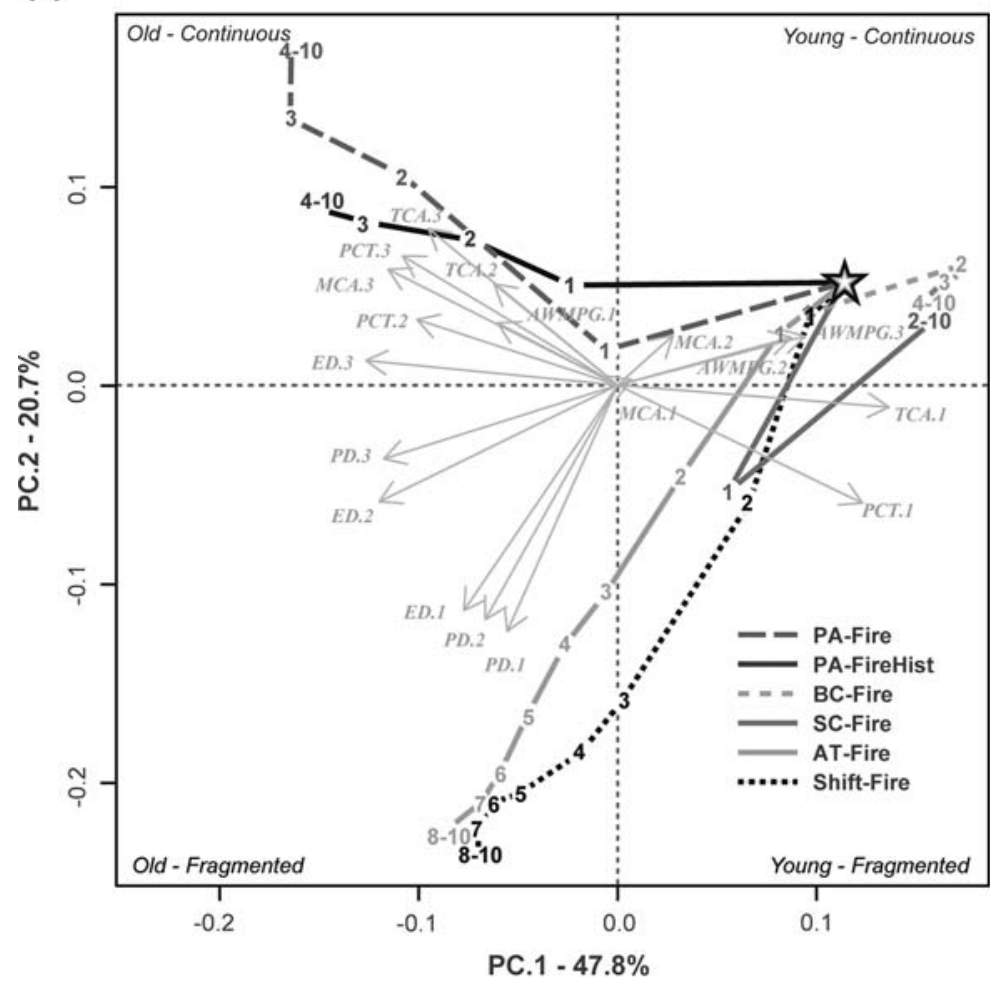

\section{(b) Without Fire}

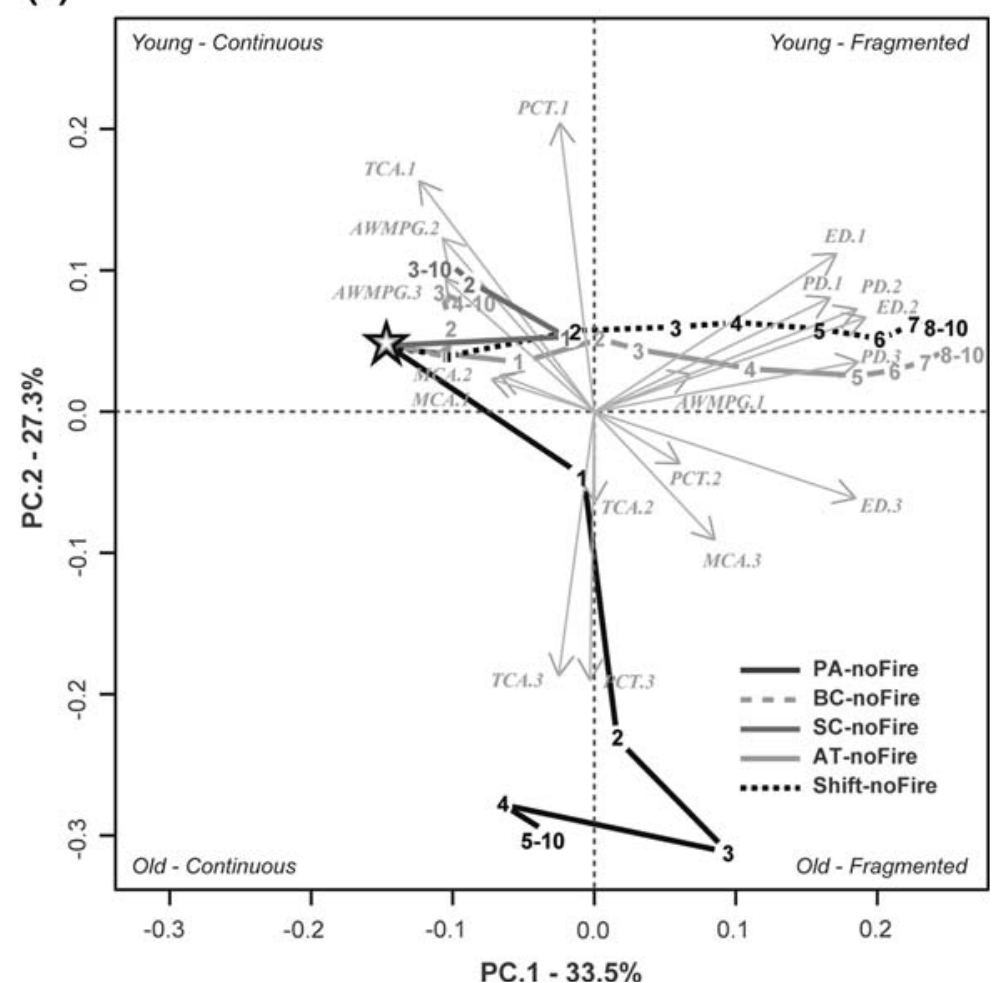

Figure 6. Principal components analysis bi-plots summarizing mean landscape metric values over 30 simulated replicates for all management types with fire (a) and without fire $(\mathbf{b})$. Initial landscape condition is indicated by a star that represents the same point in metric space in a and b. Different lines represent different management practices. See Table 1 for scenario codes. Vectors show the spatial trajectories of different management practices in 50-year timesteps; points labelled " 1 " represent years 50 , and points labelled "2" represent year 100 . Labels in the four quadrants of each figure denote interpretation of the two axes shown based on significant principal component loadings (Table 3). fragmented, older forest after 200 years. Both fire only scenarios (PA-Fire and PA-FireHist) move quickly to the upper left quadrant that corresponds with continuous old forest at a faster rate than the
AT-Fire scenario, but slower than the BC-Fire and SC-Fire scenarios as judged by the length of the vectors connecting the points at different timesteps. Only a slight difference is notable between the two 
Table 3. Summary of PCA Eigenvalues, Loading Significance, and Cumulative Variance Explained for the Principal Components Analysis

\begin{tabular}{|c|c|c|c|c|c|c|c|c|}
\hline \multirow{4}{*}{$\begin{array}{l}\text { Eigenvalue }^{1} \\
\text { Total variance explained }\end{array}$} & \multicolumn{4}{|l|}{ Fire } & \multicolumn{4}{|l|}{ No fire } \\
\hline & $\mathrm{PC} 1$ & PC2 & PC3 & PC4 & PC 1 & PC2 & PC3 & PC4 \\
\hline & 0.476 & 0.179 & 0.139 & 0.105 & 0.313 & 0.253 & 0.139 & 0.107 \\
\hline & $47.61 \%$ & $65.49 \%$ & $79.41 \%$ & $89.87 \%$ & $31.31 \%$ & $56.56 \%$ & $70.47 \%$ & $81.18 \%$ \\
\hline \multicolumn{9}{|l|}{ Loadings } \\
\hline PD.1 & 0.210 & 0.221 & 0.733 & 0.256 & 0.173 & 0.248 & 0.000 & 0.000 \\
\hline PD.2 & 0.104 & 0.501 & 0.145 & 0.119 & 0.000 & 0.401 & 0.246 & 0.109 \\
\hline PD. 3 & 0.276 & 0.106 & 0.335 & 0.111 & 0.000 & 0.394 & 0.161 & 0.215 \\
\hline ED.1 & 0.143 & 0.482 & 0.175 & 0.106 & 0.147 & 0.401 & 0.167 & 0.000 \\
\hline ED.2 & 0.263 & 0.326 & 0.113 & 0.335 & 0.000 & 0.448 & 0.000 & 0.000 \\
\hline$E D .3$ & 0.308 & 0.100 & 0.251 & 0.191 & 0.309 & 0.219 & 0.110 & 0.191 \\
\hline TCA.1 & 0.333 & 0.102 & 0.265 & 0.138 & 0.398 & 0.000 & 0.000 & 0.000 \\
\hline TCA.2 & 0.160 & 0.614 & 0.144 & 0.251 & 0.110 & 0.000 & 0.491 & 0.313 \\
\hline TCA.3 & 0.246 & 0.331 & 0.191 & 0.113 & 0.328 & 0.222 & 0.185 & 0.128 \\
\hline MCA1.1 & 0.588 & 0.126 & 0.140 & 0.343 & 0.159 & 0.134 & 0.273 & 0.509 \\
\hline$M C A 1.2$ & 0.143 & 0.568 & 0.187 & 0.241 & 0.152 & 0.000 & 0.347 & 0.484 \\
\hline MCA1.3 & 0.289 & 0.225 & 0.116 & 0.135 & 0.270 & 0.108 & 0.149 & 0.000 \\
\hline PCT.1 & 0.312 & 0.171 & 0.130 & 0.279 & 0.404 & 0.000 & 0.000 & 0.000 \\
\hline PCT.2 & 0.245 & 0.492 & 0.159 & 0.235 & 0.000 & 0.220 & 0.467 & 0.276 \\
\hline PCT.3 & 0.274 & 0.282 & 0.202 & 0.125 & 0.353 & 0.182 & 0.176 & 0.136 \\
\hline$A W M P G .1$ & 0.266 & 0.147 & 0.472 & 0.701 & 0.324 & 0.000 & 0.000 & 0.000 \\
\hline$A W M P G .2$ & 0.221 & 0.412 & 0.167 & 0.278 & 0.000 & 0.105 & 0.285 & 0.194 \\
\hline$A W M P G .3$ & 0.203 & 0.117 & 0.367 & 0.273 & 0.212 & 0.000 & 0.193 & 0.387 \\
\hline
\end{tabular}

Loadings labels represent landscape metrics and associated age category: 1, young; 2, intermediate; and 3, old. Principal component loadings in bold represent a meaningful metric that is significantly associated with its corresponding axis according to the broken stick criterion.

${ }^{1}$ Indicates that each of the first four axes is significant.

(a) Percent Target Met

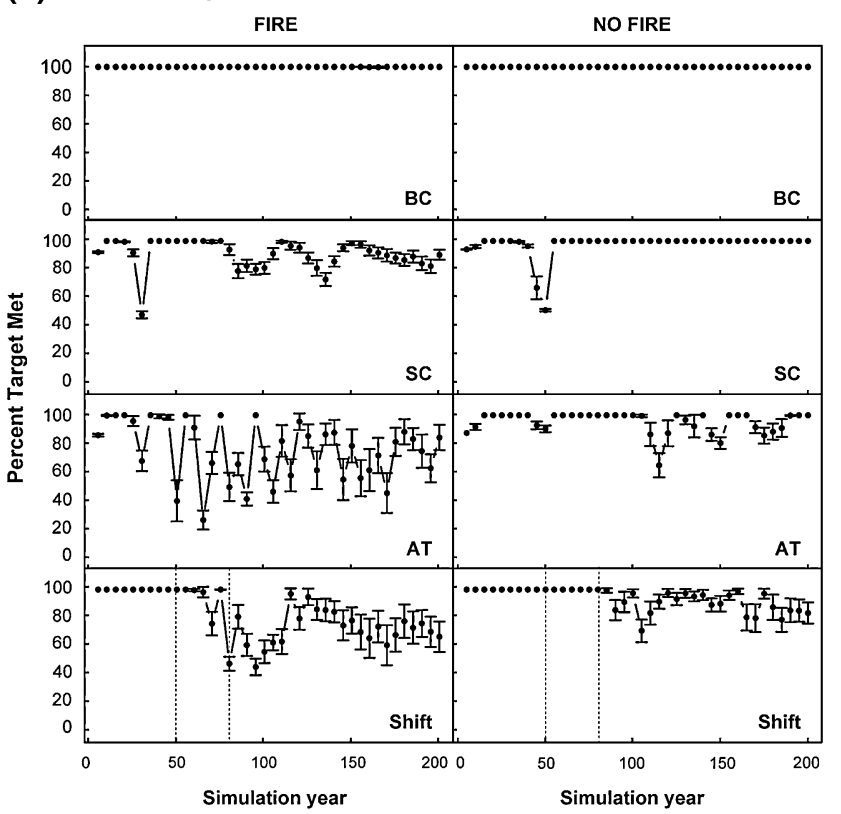

(b) Mean Harvest Age

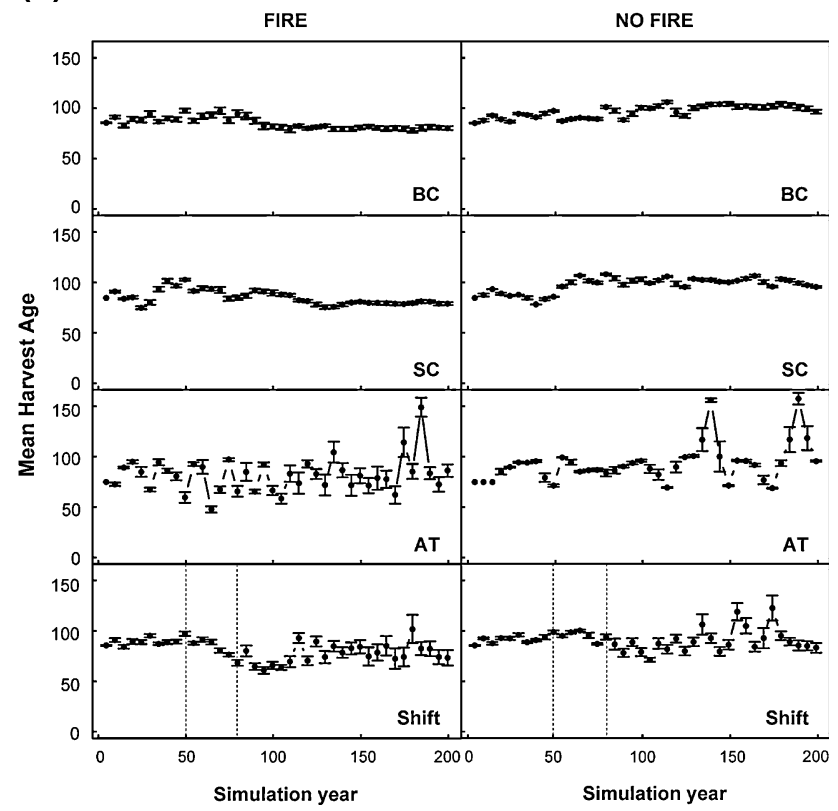

Figure 7. Harvest metrics “\% TARGET MET" and "MEAN HARVEST AGE" for each management type in the fire and nofire scenario sets. Each panel represents the mean harvest metric over 30 simulated replicates for each scenario for 200 years of simulation. Dashed vertical lines in the bottom panels represent points during the simulation in the shifting management scenarios when the management practice was changed (that is, year 50 and year 80). 
fire return intervals. The historical fire return interval scenario (PA-FireHist) reaches stability at a lower value on the forest age gradient but at a similar location on the fragmentation axis.

Without fire, the spatial trajectories of SC and BC management reach their attractor faster than the other harvest methods and at a similar rate (Figure $6 \mathrm{~b}$ ). It is interesting to note here that shifting management and AT only management types did not stray into the lower quadrants which are thought to represent older forest. Clearly the ATnoFire scenario produces more old forest, but curiously it does not show such a transition from the young-fragmented quadrant to the old-fragmented quadrant in the ordination. The best explanation is that the age gradient in this analysis has a larger range of values than scenarios with fire because of the high loadings of PCT.3 and TCA. 3 in the PA-noFire scenario. Because of these loadings, the spatial trajectory of PA-noFire expands the range of the vertical axis in the bottom half of the ordination and makes it difficult to discern the differences between BC and AT management.

An interesting result is that the shifting management with fire scenario, which ends with AT, reached the AT cluster faster than did AT management on its own (Figure 6a). Given that the shifting management scenarios had 80 years of BC and SC harvesting before implementing $\mathrm{AT}$, one might expect AC management alone to reach that cluster more quickly. However, following transition from SC to AC, the shifting management scenario covers very large areas of ordination space in just a few timesteps and overcomes the pattern created by the AT-Fire scenario to reach the general area of the final AT cluster approximately 50 years ahead of AT. In scenarios without fire, the two management types (that is, shifting management and AT) arrive at their cluster at approximately the same time (300 years), and do not show the same extent of facilitation. However, these two scenarios do reach their final cluster at the same time despite that AT-noFire has an 80-year head start over the Shift-noFire scenario. The faster rate of change in the shifting management with fire scenario than without fire indicates that both fire and management type can affect legacy duration.

\section{Harvest Attributes}

In both fire and no fire situations, $\mathrm{BC}$ management consistently met its target of 3900 ha accessed (Figure 7a). \% TARGET MET for SC with fire was similar except for a drop to approximately $50 \%$ and return to $100 \%$ between 25 and 35 years followed by a slight decline and subsequent oscillation around $80 \%$. Without fire, SC returned to $100 \%$ following a similar dip at year 30. Scenarios with fire showed greater variation in both harvest metrics than scenarios without. AT management with fire exhibited the most variability within and among timesteps for both harvest metrics. \% TARGET MET values were consistently below those observed for the BC scenarios with occasional extremely low percentages (for example, 25\%). In the shifting management scenarios, periods associated with each different management practice were similar to the individual practices with the exception that the period of AT was less variable and approached a consistent value of approximately $80 \%$ of the target area in the scenarios with fire. Most of the no fire scenarios showed marginal deviance from the $100 \%$ target indicating a consistent availability of wood.

MEAN HARVEST AGE declined slightly during the course of the first 200 years of simulation for all scenarios with fire as well as AT and shifting management scenarios without fire (Figure $7 b$ ). Harvest age increased slightly in the BC-noFire and SC-noFire scenarios, which also showed the least variability. Similar to the \% TARGET MET metric, MEAN HARVEST AGE was most variable with AT management. With fire, MEAN HARVEST AGE decreased to as low as 50 years with AT management. Less variability was observed in the AT-noFire scenario but it was still more variable than the BC-noFire or SC-noFire scenarios. In the shifting management scenario with fire, MEAN HARVEST AGE was reduced following the second transition (that is, to AT) and showed less variability than the AT-Fire scenario, but at a similar mean.

\section{Discussion}

\section{Legacy Duration}

The effects of spatial legacies were captured as temporal lags in landscape pattern following a change in management type in the ordination biplots. That the target age-class distribution was not met for up to 300 years in the age-targeted scenarios, and up to 200 years in the no-harvest scenarios illustrates that it is unlikely for new management targets to be met on the landscape within a typical rotation length or in the lifetime of forest managers. Here, the inertia in landscape level forest age patterns limited real options for management until enough time had passed for more old forest to become available. This inertia is a function of time since disturbance and the deterministic 
allocation of cut blocks that reinforce the existing age structure (Wallin and others 1994).

Several other studies have examined how different rule sets for timber harvest affect landscape scale spatial structure (Franklin and Forman 1987; Wallin and others 1994, 1996; Gustafson and Crow 1996; Gustafson 1998; Fall and others 2004; Zollner and others 2005; Didion and others 2007). However, few have done so in combination with fire and multiple shifts in forest management practices. These studies generally indicate that once established, patterns in forest age structure can remain fixed for long periods of time and can be very difficult to change, even with the implementation of new harvest rules. Wallin and others (1994) demonstrated that shifts from a dispersed to an aggregated harvest pattern did not immediately result in a change in forest attributes such as patch size and edge density. Similarly, Nonaka and Spies (2005) found that more than 100 years was required for the system to regain its historical condition in the absence of human management. Ecologically, the interactions between spatial legacies and new management practices can push forest landscape patterns out of their historical range of variability (Paine and others 1998; Schröder and others 2005), alter successional pathways, and change regional patterns of forest composition (Hessburg and others 1999; Friedman and Reich 2005).

Our simulation results support these findings and show that spatial legacies in forest age structure can persist for over 200 years. We also demonstrate that the rate at which different harvest practices reach dynamic equilibrium depends on how similar the initial conditions are to the target pattern. An unexpected result was that application of the stripcut management type before changing to age-targeted management facilitated the achievement of the age class target objectives more quickly than managing based only on AT, particularly with fire. This facilitation was due to the similarity in scale of pattern of the two different management types and how fire resets stand age and succession over large areas. Fire was also shown to affect the range of variability exhibited by landscape pattern metrics and aspatial harvesting measures indicating that changes in the fire regime can have significant implications for sustainable forest management.

\section{Shifting Management Scenarios and Spatial Trajectories}

The shifting management scenarios did not result in any dramatic cumulative effects on forest structure such as alternate stable states (Paine and oth- ers 1998) but did exhibit temporal lags in pattern following shifts. Simulations eventually converged at the same stable equilibrium as the final management practice without regard for which practices preceded them, or how frequently they were changed. However, the rates at which the spatial trajectory changed differed due to pattern reinforcing effects of similar scales of management and the pattern changing effects of fire.

Acceleration in the rate of change of forest age structure towards the AT management target in the shifting management scenarios was in part due to increased fragmentation created by the 30 years of strip cutting that preceded it. When interrupted with a shift to AT, the strip-cutting strategy left scattered areas of different (that is, older) ages that were used to satisfy the AT goals, which also produces fine scale fragmentation. In effect, SC management acted to facilitate AT management targets. The fine scale patchiness created by SC made it possible for AT management to overcome the constraints of large-scale patchiness created by fires and $\mathrm{BC}$ management.

SC management was able to help AT management meet its goals because they both produce patterns with a high degree of fragmentation shown by the movement of their spatial trajectories towards quadrants associated with fragmented forest in the ordination bi-plots (Figure 6a, b). If spatial adjacency constraints were included in AT management to guarantee contiguous patches, the strip cut method would not have helped it reach its goals because the different management types would be asynchronous with respect to spatial scale. Similarly, the fluctuations in harvest area and spatial metrics in the AT-Fire scenario reflect the lack of synchrony between spatial structure created by fire, and that created by AT management.

\section{Interactions with Fire}

Simulations without fire displayed similar rates of change in spatial attributes to those with fire, and reached similar relative final stable equilibria with the exception of the shifting management, which, when combined with fire reached its goals faster (Figure 6). Fire helped shifting management reach its new management goals, beyond the help conferred by the fine scale patchiness of SC management by replacing potentially constraining spatial structure with large areas of young forest. This shows that fire can reduce the duration of landscape legacies in forest age structure. However, the degree to which fire can change the spatial age structure created through management will likely 
depend on the relative spatial and temporal scales of fire and forest management.

The percent of the harvest target met and mean harvest age show that more area for timber extraction was available without fire and that fire and logging compete for timber (Bergeron and others 2004a). In addition to reducing the values of these harvest metrics, fire increased variability within and among timesteps, particularly with agetargeted management. The shifting management scenarios showed less variability during the agetargeted period than did age-targeted alone indicating that strip-cutting can assist age-targeted management achieve its aspatial goals as well as its spatial age class targets. High variability in the percent of harvest target met suggests that age class targeted management can affect timber flow, especially when combined with fire, and that ecosystem oriented management regimes will likely not be successful without corresponding reductions in harvest rate. These findings support those of Fall and others (2004) who also note that economic uncertainty combined with uncertain fire regimes require flexible management plans to ensure the persistence of diverse habitat types across the landscape.

Several simplifying assumptions were made in this simulation study, in particular for the fire and harvest sub-models. We used a statistical fire model to simulate stand replacing crown fires that burn independent of weather, terrain, and site conditions. A statistical fire model was used because it allowed us to control the variability in size and frequency of fires based on historical data. Ecologically, the assumption of a constant fire risk relative to stand age is based on a theoretical exponential distribution of forest age at the landscape scale in boreal forest regions (Van Wagner 1978; Boychuk and others 1997; Bergeron and others 2004b). An exponential forest age distribution implies independent fire return times and constant fire risk (Boychuk and others 1997). Age-independence was also assumed because large stand-replacing fires (1) occur under extreme weather conditions; (2) account for more than $97 \%$ of the area burned (Stocks and others 2002); and (3) do not distinguish young from old stands (Johnson and others 2001; Lefort and others 2003). Our findings are specific to the assumptions of the fire model we used. For example, an age-dependent model would be expected to produce less area of old forest when compared to an age-independent model and would also affect the long-term average fire size and return frequency. In the age-independent model we used, variability in fire size and frequency are not emergent properties, but are fixed as control parameters.

We used an area-based annual allowable cut (AAC) rather than a volume based AAC in which area accessed varies in response to available volume. An area-based AAC is desirable because it allows greater control and transparency in the forest management process and deals in the same currency as the modelled fire process (that is, forest area). Without such control our results would not only contain information about the spatial patterns in forest age from fire and management type, but also that due to changes in area harvested. The actual area accessed (\% TARGET MET) was used as an indicator of constraints imposed on logging by previous management and fire. In this light, our simulation output should be seen as the consequence of interactions among assumptions, hypotheses, and initial conditions rather than an attempt to predict the future state of the forest (Baker 1992). The forest patterns we simulated reflect interactions among simplified models of forest disturbance and demonstrate the potential long-term consequences of these assumptions and importance of landscape-scale spatial legacies to sustainable forest management planning.

Our approach was distinct from previous efforts to examine landscape legacies in three important ways. (1) We simulated management, fire, and forest growth using a spatial stochastic model, wherein many replicates were performed to explicitly include the effects of stochastic disturbance (that is, fire). (2) We examined a dynamic policy environment in which the rules governing harvest change over time with the explicit goal of investigating how multiple management practices may cumulatively affect forest dynamics through time. And, (3) our method of analysis involved examining changes in multiple spatial landscape metrics that were summarized and interpreted using ordination and significance testing.

\section{Conclusions}

We showed that spatial legacies of landscape disturbances can have long-term effects on the location and timing of management activities. Whether legacies constrain or facilitate new management objectives is dependent on the character of the new process being imposed. Although we limit ourselves to discussing larges scale legacies in forest age structure, legacies also manifest as other ecological attributes such as species composition and succession (for example, Friedman and Reich 2005), nutrient availability, and coarse woody debris. All 
have important implications for biodiversity persistence and sustainable management. Additional disturbances such as insects, wind, and disease also contribute important legacies to forest structure, but were not simulated in this study. Further research into how legacies affect ecosystem attributes at multiple spatial and temporal scales is essential to a better understanding of how they can best be manipulated to successfully achieve new sustainable management goals.

The desired effects of alternate "disturbance emulating" harvest regimes are not likely to be observed within a traditional rotation time frame. Given that current management practices determine potential future forest patterns (Nelson and Finn 1991), dependent upon uncertain interactions among fire, harvest, and forest succession, forest managers are faced with significant challenges when making long-term plans. This research suggests that one method of addressing spatial legacies is to not over commit to a particular forest management practice by harvesting up to the theoretical maximum. Future changes and uncertainty will be more likely accommodated by more intact forest that will increase the real options available to future managers. Without such a system buffer, spatial patterns can become "locked in" and new management practices will not meet their objectives without violating important ecological constraints or economic targets. An increased awareness of how legacies affect ecosystem dynamics offers a useful way to conceptualize and interact with the complex spatial and temporal relationships that exist among forest management, natural disturbance, and succession and should be used to further refine ecosystemic management goals.

\section{ACKNOWLEDGEMENTS}

The work was funded through NSERC PGS-A and CFS-NSERC supplement to PJ and Sustainable Forest Management Network NCE grants to CM and others and DK and others. We would also like to acknowledge the help of B. Rayfield and two anonymous reviewers whose comments greatly improved the quality of manuscript.

\section{REFERENCES}

Baker WL. 1992. The landscape ecology of large disturbances in the design and management of nature reserves. Landsc Ecol 7:181-94.

Bergeron Y, Leduc A, Harvey BD, Gauthier S. 1999. Forest management guidelines based on natural disturbance dynamics: stand- and forest-level considerations. For Chron 75:49-54
Bergeron Y, Gauthier S, Kafka V, Lefort P, Lesieur D. 2001. Natural fire frequency for the eastern Canadian boreal forest: Consequences for sustainable forestry. Can J For Res 31:38491.

Bergeron Y, Leduc A, Harvey BD, Gauthier S. 2002. Natural fire regime: a guide for sustainable management of the Canadian boreal forest. Silva Fennica 36:81-95.

Bergeron Y, Flannigan M, Gauthier S, Leduc A, Lefort P. 2004. Past, current and future fire frequency in the Canadian boreal forest: Implications for sustainable forest management. Ambio 33:356-60.

Bergeron Y, Gauthier S, Flannigan M, Kafka V. 2004. Fire regimes at the transition between mixedwood and coniferous boreal forest in northwestern Quebec. Ecology 85:1916-32.

Bouchard M, Kneeshaw DD, Messier C. 2007. Forest dynamics following spruce budworm outbreaks in the northern and southern mixedwoods of central Quebec. Can J For Res 37:763-72.

Boychuk D, Perera AH, Ter-Mikaelian M, Martell DL, Li C. 1997. Modelling the effect of spatial scale and correlated fire disturbance on forest age distribution. Ecol Modell 95:145-64.

Burton PJ, Kneeshaw DD, Coates KD. 1999. Managing forest harvesting to maintain old growth in boreal and sub-boreal forests. For Chron 75:623-31.

D`Eon RG, Glenn SM. 2005. The influence of forest harvesting on landscape spatial patterns and old-growth-forest fragmentation in southeast British Columbia. Landsc Ecol 20:19-33.

Didion M, Fortin MJ, Fall A. 2007. Forest age structure as indicator of boreal forest sustainability under alternative management and fire regimes: a landscape level sensitivity analysis. Ecol Modell 200:45-58.

Fahrig L. 2003. Effects of habitat fragmentation on biodiversity. Annu Rev Ecol Evol Syst 34:487-515.

Fall A, Fall J. 2001. A domain specific language for models of landscape dynamics. Ecol Modell 141:1-18.

Fall A, Fortin M-J, Kneeshaw DD, Yamasaki SH, Messier C, Bouthillier L, Smith C. 2004. Consequences of various landscape-scale ecosystem management strategies and fire cycles on age-class structure and harvest in boreal forests. Can J For Res 34:310-22.

Fortin M-J, Dale MRT. 2005. Spatial analysis. Cambridge: Cambridge University Press.

Franklin JF, Forman RTT. 1987. Creating landscape patterns by forest cutting: ecological consequences and principles. Landsc Ecol 1:5-18.

Friedman SK, Reich PB. 2005. Regional legacies of logging: Departure from presettlement forest conditions in northern Minnesota. Ecol Appl 15:726-44.

Galindo-Leal C, Bunnell FL. 1995. Ecosystem management: implications and opportunities of a new paradigm. For Chron 71:601-6.

Gray DR, Régnière J, Boulet B. 2000. Analysis and use of historical patterns of spruce budworm defoliation to forecast outbreak patterns in Quebec. For Ecol Manage 127:217-31.

Gustafson EJ. 1998. Clustering timber harvests and the effect of dynamic forest management policy on forest fragmentation. Ecosystems 1:484-92.

Gustafson EJ, Crow TR. 1996. Simulating the effects of alternative forest management strategies on landscape pattern. J Environ Manage 46:77-94.

Gustafson EJ, Zollner PA, Sturtevant BR, He HS, Mladenoff DJ. 2004. Influence of forest management alternatives and land 
type on susceptibility to fire in northern Wisconsin, USA. Landsc Ecol 19:327-341.

He HS, Mladenoff DJ. 1999. Spatially explicit and stochastic simulation of forest-landscape fire disturbance and succession. Ecology 80:81-99.

Hessburg PF, Salter RB, Smith BG. 1999. Detecting change in forest spatial patterns from reference conditions. Ecol Appl 9:1232-52.

Hunter ML. 1993. Natural fire regimes as spatial models for managing boreal forests. Biol Conserv 65:115-20.

Jackson DA. 1993. Stopping rules in principal components analysis: a comparison of heuristical and statistical approaches. Ecology 74:2204-14.

James PMA, Rayfield BR, Fortin M-J, Fall A, Farley G. 2005. Reserve network design combining spatial graph theory and species' spatial requirements. Geomatica 59:323-33.

Johnson EA. 1992. Fire and vegetation dynamics: Studies from the North American boreal forest. Cambridge University Press, Cambridge.

Johnson EA, Van Wagner CE. 1985. The theory and use of two fire history models. Can J For Res 15:214-20.

Johnson EA, Miyanishi K, Bridge SRJ. 2001. Wildfire regime in the boreal forest and the idea of suppression and fuel buildup. Conserv Biol 15:1554-7.

Jongman RHJ, Ter Braak CJF, Tongeren OFRvan, Eds. 1987. Data analysis in community and landscape ecology. Pucdoc, Wageningen: Cambridge University Press.

Kneeshaw DD, Leduc A, Drapeau P, Gauthier S, Pare D, Carignan R, Doucet R, Bouthillier L, Messier C. 2000. Development of integrated ecological standards of sustainable forest management at an operational scale. For Chron 76:481-93.

Lefort P, Gauthier S, Bergeron Y. 2003. The influence of fire weather and land use on the fire activity of the lake Abitibi area, eastern Canada. For Sci:509-21.

Li C, Ter-Mikaelian M, Perera AH. 1997. Temporal fire disturbance patterns on a forest landscape. Ecol Modell 99:137-150.

Li H, Franklin JF, Swanson FJ, Spies TA. 1993. Developing alternative cutting patterns: a simulation approach. Landsc Ecol 8:63-75.

McGarigal K, Marks BJ. 1995. FRAGSTATS: spatial pattern analysis program for quantifying landscape structure. In: USDA For. Serv. Gen. Tech. Rep. PNW-351.

Messier C, Kneeshaw DD. 1999. Thinking and acting differently for sustainable forest management. The Forestry Chronicle 75:929-38.

Nelson JD, Finn ST. 1991. The influence of cut block size and adjacency rules on harvest levels and road networks. Can J For Res 21:595-600.
Nonaka E, Spies TA. 2005. Historical range of variability in landscape structure: A simulation study in Oregon, USA. Ecol Appl 15:1727-46.

O’Brien D, Manseau M, Fall A, Fortin M-J. 2006. Testing the importance of spatial configuration of winter habitat for woodland caribou: an application of graph theory. Biol Conserv 130:70-83.

O`Neil RV, Krummel JR, Gardner RH, Sugihara G, Jackson B, DeAngelis DL, Milne BT, Turner MG, Zygmunt B, Christensen SW, Dale VH, Graham RL. 1988. Indices of landscape pattern. Landsc Ecol 1:153-62.

Paine RT, Tegner MJ, Johnson EA. 1998. Compounded perturbations yield ecological surprises. Ecosystems 1:535-45.

Peres-Neto PR, Jackson DA, Somers KM. 2003. Giving meaningful interpretation to ordination axes: assessing loading significance in principal component analysis. Ecology 84:2347-63.

Pielou EC. 1984. The interpretation of ecological data. New York: Wiley.

R Development Core Team. 2005. R: A language and environment for statistical computing. Austria: R Foundation for Statistical Computing Vienna.

Remmel TK, Csillag F. 2003. When are two landscape pattern indices significantly different?. J Geogr Syst 5:331-51.

Rowe JS. 1972. Forest regions of Canada. Ottawa: Information Canada.

Schröder A, Persson L, De Roos AM. 2005. Direct experimental evidence for alternative stable states: a review. Oikos 110:3-19.

Stocks BJ, Mason JA, Todd JB, Bosch EM, Wotton BM, Amiro BD, Flannigan MD, Hirsch KG, Logan KA, Martell DL, Skinner WR. 2002. Large forest fires in Canada, 1959-1997. J Geophys Res 108:8149. doi:8110.1029/2001JD000484 [printed 000108(D000481), 002003].

Van Wagner CE. 1978. Age-class distribution and the forest fire cycle. Can J For Res 8:220-7.

Wallin DO, Swanson FJ, Marks B. 1994. Landscape pattern response to changes in pattern generation rules: land-use legacies in forestry. Ecol Appl 4:569-80.

Wallin DO, Swanson FJ, Marks B, Cissel JH, Kertis J. 1996. Comparison of managed and pre-settlement landscape dynamics in forests of the Pacific Northwest, USA. For Ecol Manage 85:291-309.

Zollner PA, Gustafson EJ, He HS, Radeloff VC, Mladenoff DJ. 2005. Modeling the influence of dynamic zoning of forest harvesting on ecological succession in a northern hardwoods landscape. Environ Manage 35:410-25. 